\title{
Systematic review of the influence of socioeconomic deprivation on mortality after colorectal surgery
}

Poulton TE ${ }^{12}$, Salih $\mathrm{T}^{3}$, Martin P 12, Rojas-Garcia A 2 , Raine R ${ }^{2}$, Moonesinghe SR 124

1. Health Service Research Centre, National Institute of Academic Anaesthesia, Royal College of Anaesthetists

2. Department of Applied Health Research, University College London

3. Central London School of Anaesthesia

4. University College London Hospitals' NIHR Surgical Outcomes Research Centre

\section{Corresponding author:}

Thomas Poulton

t.e.poulton@doctors.org.uk

106 Grosvenor Road

Jesmond

Newcastle Upon Tyne

NE2 2RQ

07941139157

Twitter: @TomPoulton

Funding:

No specific funding was awarded to support this study.

TP receives funding from the NIAA Health Services Research Centre at the Royal College of Anaesthetists for his role as a research fellow.

SRM receives funding from the UCLH Biomedical Research Centre where she is member of the faculty; she also receives funding from the Health Foundation as an Improvement Science fellow and for her role as Director of the NIAA Health Services Research Centre at the Royal College of Anaesthetists.

RR and AR-G were supported (RR in part, AR-G fully) by the National Institute for Health Research (NIHR) Collaboration for Leadership in Applied Health Research and Care (CLAHRC) North Thames at Bart's Health NHS Trust.

The views expressed are those of the author(s) and not necessarily those of the NHS, the NIHR, the NIAA, or the Department of Health.

Manuscript category:

Review

Based on previous communication:

No 


\section{Abstract}

Background:

Socioeconomic deprivation is a potentially important factor influencing surgical outcomes. This systematic review aimed to summarise the evidence for any association between socioeconomic group and mortality after colorectal surgery, and to report the definitions of deprivation used and the approaches taken to adjust for comorbidity in this patient population.

Methods:

MEDLINE, EMBASE, The Cochrane Library, and Web of Science (up to November 2016) were searched for studies on adult patients undergoing major colorectal surgery, which reported on mortality according to socioeconomic group. Risk of bias and study quality were assessed by extracting data relating to study size and variations in inclusion and exclusion criteria. Quality was assessed using a modification of a previously described assessment tool.

Results:

The literature search identified 59 studies published between 1993 and 2016, reporting on 2698403 patients from eight countries. Overall findings showed evidence for higher mortality in more deprived socioeconomic groups, both in the perioperative period and in the longer term.

Studies differed in how they defined socioeconomic groups, but the most common approach was to use one of a selection of multifactorial indices based on small geographical areas. There was no consistent approach to adjusting for comorbidity, but where this was considered the Charlson Comorbidity Index was most frequently used.

Conclusion:

This systematic review suggests that socioeconomic deprivation influences mortality after colorectal surgery.

Keywords: 
Socioeconomic Factors [N01.824]

Colorectal Surgery [H02.403.810.208]

Laparotomy [E04.406]

Postoperative Period [E04.614.750]

Mortality [L01.280.975.550] 


\section{Introduction}

Colorectal surgery encompasses a wide and heterogeneous range of potential presentations, pathologies and procedures. This may include planned surgery, for instance for bowel cancer, or emergency procedures for pathologies such as acute bowel obstruction or faecal peritonitis. Major colorectal surgery has postoperative mortality rates similar to or higher than some operations that would traditionally be considered as 'high-risk'. Thus major resections for colorectal cancer have similar or higher rates of 30-day mortality when compared to elective abdominal aortic aneurysm repair (5.8-6.8\% compared to 3.2-6.8\%) or primary cardiac surgery (around 3\%). ${ }^{1-5}$ Emergency surgery is particularly high risk, with a 30-day mortality rate following emergency laparotomy of around $11 \% .^{6}$

Although lower socioeconomic group has an established association with increased mortality from a range of cardiovascular and cerebrovascular diseases, and an increased prevalence of multimorbidity, ${ }^{78}$ there are relatively few studies investigating the association between socioeconomic group and mortality after colorectal surgery.

There are several potential reasons for variation in mortality between socioeconomic groups. These include barriers to accessing healthcare, such as associated financial costs or geographical distances in rural communities. There may be variation in the availability and quality of healthcare provided in areas of greater deprivation, ${ }^{9}$ or differences in health-seeking behaviour. ${ }^{10}$ Differences between socioeconomic groups in lifestyle factors such as diet, exercise, smoking and levels of alcohol consumption, ${ }^{11-15}$ coupled with variations in the prevalence and severity of comorbidities such as obesity, type 2 diabetes, lung disease, and cardiovascular and cerebrovascular diseases may also contribute. ${ }^{7816-18}$ Overall, socioeconomic group is associated with significant differences in life expectancy, even between relatively small geographical areas. ${ }^{19} 20$

The main aim of this review was to summarise the evidence for any association between socioeconomic group and postoperative mortality following colorectal surgery after adjustment for other case-mix variables. It was hypothesised that more deprived patients have higher mortality after 
colorectal surgery. Additional objectives were to identify the measures of socioeconomic group used in this field, and to identify the approaches taken in adjusting for comorbidity. 


\section{Methods}

The protocol for this review was published on the PROSPERO online database of systematic reviews (CRD42016051592). This review followed the PRISMA checklist (Appendix 1).

A search was performed using MEDLINE, EMBASE, the Cochrane Library, and Web of Science, and the results were imported into reference management software (EndNote X7.7.1, Clarivate Analytics, Philadelphia PA). For each of the four searches, the entire database was included up to and including 2 November 2016, with no further date restrictions or limits applied. The full search strategies and date ranges are detailed in Appendix 2.

\section{Study selection and data extraction}

After removal of duplicates, manual screening was performed on the title and abstract of the articles found by the database searches. Articles with no relevance to the effect of socioeconomic group on mortality after colorectal surgery were excluded. Those papers where relevance to this review was either probable or possible based on the title and abstract were reviewed in full using the following inclusion criteria: adult patients aged 18 years or older, patients undergoing a colorectal surgical procedure, studies reporting a mortality-based outcome according to a measure of socioeconomic group. Exclusion criteria were: cohorts including patients under the age of 18 years, cohorts including patients who did not undergo an eligible surgical procedure (e.g. non-colorectal procedures on the bowel or intraabdominal gastrointestinal tract, surgery following blunt or penetrating trauma, nonsurgical conservative management), studies in which the measure of socioeconomic group was based solely on educational attainment or ethnicity, conference abstracts or posters.

While education does contribute to multifactorial measures of deprivation such as the Index of Multiple Deprivation and the Socioeconomic Indexes for Areas, educational attainment in isolation was not considered to be a sufficient surrogate for socioeconomic deprivation for the purposes of this review. 2122 
Following completion of the screening, the reference lists and citations of all included papers were manually searched to identify any additional articles that could be included in the review that had not been identified through the database search. This process was repeated until no new articles were identified.

Data extraction was independently undertaken by two of the authors using standardised, purpose built tables relating to study characteristics, quality, and outcomes (Appendix 3 and 4). Inclusion and exclusion criteria were extracted to record variation between studies, assessing if patients were excluded on the basis of any sociodemographic or clinical characteristic. Study quality was independently assessed by the same two authors according to a modification of a previously used questionnaire (Appendix 5 and 6$) \cdot{ }^{23}$

Rates of missing data were assessed based on any loss to follow-up or exclusions from reviews of administrative databases at the time of analysis. Differences in treatment strategies between the socioeconomic groups that could potentially have a causal influence on postoperative mortality were extracted. Examples of this could include differences in the rates of perioperative chemo/radiotherapy, or differences in the surgical technique or approach used.

\section{Data analysis and statistics}

Data pertaining to the magnitude and statistical significance of differences in mortality between socioeconomic groups were extracted where presented. The presentation of data varied between studies and included mortality and survival rates, or regression coefficients, for which $p<0.05$ was considered statistically significant. Other studies presented the data as odds ratios, risk ratios, or hazard ratios, for which statistical significance was judged based on $95 \%$ confidence intervals that did not include the value 1.

Data were further examined to classify results according to short-term and longer-term mortality outcomes, surgical urgency, the aims of surgery, the model of healthcare provision described in the article, and time period. 


\section{Results}

\section{Search results and quality assessment}

Following the initial database searches, 22272 articles were manually screened by title and abstract. After the first round of screening, 53 articles were found eligible for inclusion. A further six articles citing or cited by those 53 articles were identified that met the inclusion criteria and had not been found by the database search strategy (Figure 1).

This review thus included 59 articles published between 1993 and 2016 and reports on a total of 2 698403 patients. These studies included data collected between 1976 and 2014 from eight countries. Twenty-five studies were based in the United Kingdom, 24 in the USA, three in Australia, two in each of Denmark and The Netherlands, and one each in France, Sweden and Taiwan.

A first review of the studies revealed that the published evidence was too heterogeneous to enable a meta-analysis to be undertaken. There was wide variation in patient cohorts, outcome measures, and measures of socioeconomic group. Moreover, the effect of socioeconomic group on outcomes was not always the main research question and instead was reported as part of a multivariate analysis with a different focus. Comparison between countries with different approaches to defining socioeconomic groups risked significant bias. Indeed, even studies using a single measure such as the Index of Multiple Deprivation cannot be directly compared between different countries in the United Kingdom without adjustment due to differences in how the deprivation score is calculated. ${ }^{24}$ This review is therefore limited to descriptive analysis.

\section{Quality assessment}

The assessment of quality of the papers included in the review is summarised in Appendix 3 and Appendix 6. Overall, agreement between the two assessors was good, where there were differences one of the authors resolved the query by referring again to the original article. 
Seven studies were single centre and 52 included data from multiple centres. There were no multinational studies. Two of the studies were randomised controlled trials, ${ }^{25} 26$ with the remaining 57 being observational. Forty-seven studies were based on reviews of administrative data or data held in disease registries. The remaining 12 studies were based on data prospectively or retrospectively collected.

There is no validated tool to provide a single overall assessment of quality for the types of studies included in this review. Instead quality was assessed across a range of domains such as method, risk of bias, sample size, and analysis (Figure 2). Forty-nine studies were rated 'Good' or 'Fair' across all domains. Excluding those studies rated as 'Poor' in relevant quality assessment domains did not alter the proportion of manuscripts finding associations between socioeconomic group and mortality.

Twenty-four studies used unselected cohorts of patients undergoing colorectal surgery, however 35 excluded some patients, most commonly on the basis of age or, in the case of cancer surgery, advanced disease stage. Examples of other exclusions included non-curative surgery, surgical urgency, or treatment with adjuvant or neoadjuvant therapies. In studies performed in countries with insurance-based healthcare systems, some patients were excluded according to payer status.

Rates of missing or excluded data were examined to evaluate loss to follow-up in prospectively collected data, missing data within administrative databases, or other exclusions from the analysis. This was judged to have been present in 12 studies that excluded patients with missing data. Four studies excluded patients who died within 30 days of surgery from their analysis of longer-term survival. ${ }^{27-30}$ One study, focusing on 'failure to rescue', performed mortality outcome analysis only on those patients with a recorded postoperative complication. ${ }^{31}$

\section{Adjustment for confounding}

Forty-seven studies performed case-mix adjustment in at least one of their analyses. The specifics of variables included in the adjustment are listed in Appendix 4 and are summarised in Table 1. Thirtyeight studies included a measure of patient comorbidities or fitness; the most commonly used comorbidity summary measure was the Charlson index (used in 22 studies). 


\section{Main findings}

Forty-four out of 59 studies (75\%) identified an association between reported mortality outcomes and socioeconomic group in either unadjusted or adjusted analysis. Considering only the 43 studies that used adjustment for confounders and were rated 'Good' or 'Fair' in the quality domains assessing method, risk of bias, sample size, and analysis, 33 concluded that socioeconomic group was independently associated with mortality. In all these cases, socioeconomic disadvantage was found to predict higher mortality.

The remainder of the results section will report on whether these results are sensitive to different methods of measuring socioeconomic group, and whether they vary by outcome measure, urgency of surgery, aim of surgery, country-specific model of healthcare provision, and time.

\section{Methods of assessment of socioeconomic group}

Methods for measuring socioeconomic group varied between studies, with some studies repeating their analysis using more than one measure. The most common descriptor was one of a selection of indices of deprivation based on a patient's area of residence (used in 28 of the articles). These included the Carstairs index, used 14 times; the Index of Multiple Deprivation (seven times); the Townsend index and the Socioeconomic Indexes for Areas (three times each); and the Scottish Index of Multiple Deprivation (once). Within these 28 studies, 20 undertook risk-adjusted analyses, of which 12 concluded that lower socioeconomic group was associated with worse outcome after riskadjustment.

Insurance or payer status was used to describe socioeconomic group 15 times. Within this subgroup, seven of the 12 studies that adjusted for other risk factors found higher mortality to be associated with lower socioeconomic group. 
Thirteen studies used income as a measure of socioeconomic group, based either on a median figure for a patient's area of residence or individual patient-level data. The poverty rate within the patient's area of residence was used in four studies. Twelve of the studies basing their analysis on income and all of the studies based on poverty adjusted for potential confounding variables. Ten and four studies respectively concluded that there was an association between greater mortality and lower socioeconomic group on adjusted analysis.

Even among studies that used the same measure of socioeconomic group, there was considerable variation in how the subgroups were defined. For instance, studies using the Carstairs index variably treated scores of one to seven as separate categories, grouped patients together according to ranges of scores to form a smaller number of sub-categories, or used the index to divide their population into quartiles or quintiles. When grouped into quartiles, some studies analysed each quartile independently whereas one compared the most deprived quartile with the remaining three quartiles grouped together. Thus, the specific definition of deprivation often differed between studies, even when the same measure was used.

\section{Outcome measures}

Mortality endpoints included in-hospital mortality; mortality at 30 or 90 days; mortality one, two, three or five years after surgery; or longer-term survival analysis, with the longest follow-up period being 20 years. Mortality was predominantly reported as all-cause, but in seven articles the disease-specific figure was reported. ${ }^{28} 3032-36$

Of the 39 studies that evaluated in-hospital or 30-day postoperative mortality, 29 adjusted for potential confounders and 21 of these found that lower socioeconomic group was independently associated with higher mortality. All of the 29 studies that reported case-mix adjusted short term outcomes were assessed as 'Good' or 'Fair' in domains assessing method, risk of bias, sample size and analysis.

Thirty-three studies looked at longer-term mortality outcomes, such as survival at 1-5 years, or overall survival time. Twenty-seven of these adjusted for confounders, of which 20 found an independent 
association between lower socioeconomic group and higher mortality. Excluding the studies rated 'Poor' in domains assessing method, risk of bias, sample size, and analysis, 17 out of 23 found that lower socioeconomic group and worse longer-term outcomes were independently associated.

Findings for the most common methods of assessing socioeconomic group and follow-up periods are summarised in Table 2. Other study attributes and the corresponding numbers of patients are shown in Table 3.

\section{Surgical urgency}

Thirty-five studies reported outcomes for cohorts that comprised a mixture of elective and non-elective surgery, while 19 articles did not report the urgency of surgery. Three studies analysed data for cohorts undergoing only non-elective surgery, and two of these found an association between socioeconomic group and mortality. Two of these studies measured both 30-day and 1-year mortality and found associations between lower socioeconomic group and higher mortality at both endpoints. ${ }^{37}$ ${ }^{38}$ The study that did not find an association measured both 5-year all-cause and disease-specific survival rates, but was a smaller cohort and did not undertake case-mix adjustment as part of that analysis. ${ }^{32}$

Three articles reported outcomes for cohorts undergoing only elective surgery, all of which were based in countries providing a universal access healthcare system. One of these found an association between lower socioeconomic group and higher all-cause mortality at 30-days and 1-year after adjustment for confounders. ${ }^{39}$ One study, looking at 30-day all-cause mortality, found no such association after case-mix adjustment. ${ }^{40}$ The third study was smaller and based in a single centre, and found no difference in all-cause or disease specific unadjusted 5-year survival. ${ }^{30}$

\section{Aims of surgery}

The majority of studies (41 out of 59) did not report whether the surgical procedure was performed with curative or palliative intent. Seven studies reported outcomes for patients undergoing either curative or palliative surgery combined. 
Of seven studies of patients undergoing cancer surgery with curative intent that adjusted for confounders, all identified an association with lower socioeconomic group and higher all-cause mortality. Six of these studies measured longer-term outcomes (5 years or longer) after curative surgery for colorectal cancer and found that risk-adjusted all-cause mortality was higher in more deprived socioeconomic groups.

Two articles reported the outcomes of subgroups undergoing palliative procedures. These cohorts were relatively small and reported only crude mortality or survival rates without case-mix adjustment. ${ }^{32} 35$ Neither study identified an association between socioeconomic group and outcome.

\section{Models of healthcare provision}

The studies included in this review were based on data collected in eight different countries, each with varying approaches to funding healthcare. Of the 21 studies based in countries with privatised healthcare systems that performed case-mix adjustment, 19 found an independent association between lower socioeconomic group and increased mortality. This compared to 17 of the 26 studies based in countries with state-funded systems.

Ten studies based in the United States found associations between socioeconomic group and certain hospital characteristics. In eight studies, more deprived patients were more likely to be admitted to low volume hospitals; $2941-47$ in three studies, more deprived patients were more like to have their surgery performed by low volume surgeons; 294245 and two studies found that lower socioeconomic group was associated with admission to a hospital in a rural location. 4849

\section{$\underline{\text { Time period }}$}

There have been considerable changes in healthcare technologies, medical training, surgical techniques, and public awareness over the time the data for the studies included in this review were 
collected. Studies were therefore divided into an early period (data collected between 1976 and 1999) and a late period (data collected between 2000 and 2014).

Twenty studies collected data between 1976 and 1999, 27 studies collected data between 2000 and 2014, while the remaining studies' data collection spanned both the early and late periods. Seventeen of the studies in the early period reported case-mix adjusted outcomes, of which 12 found that lower socioeconomic group was associated with higher postoperative mortality. This compared to 16 out of 20 studies in the late period that also found higher postoperative mortality to be associated with lower socioeconomic group after case-mix adjustment. 


\section{Discussion}

This systematic review examined the association between socioeconomic group and mortality after colorectal surgery. Both studies that explicitly aimed to estimate the effect and studies that measured it as part of an investigation into other research questions were taken into account. While the available literature did not allow a meta-analysis to be performed, the majority of studies showed evidence of an association between increased mortality, both short- and long-term, and more deprived patient groups.

The relationship between socioeconomic group and mortality after colorectal surgery may be explained by factors relating to health status, healthcare provision, or broader societal factors. Different factors may have varying magnitudes of effects depending on the temporal endpoint used.

Possible explanations for differences in mortality include patient-specific factors such as comorbidities and health-related behaviour. Numerous patient factors that have been associated with adverse outcomes after major surgery are more prevalent in cohorts of more socioeconomically deprived patients. These include higher rates of smoking, rates of both obesity and malnutrition, and rates of type 2 diabetes mellitus. ${ }^{8131416}$ Patients with comorbidities are more likely to experience complications postoperatively, and complications have been associated with an increased risk of premature death, stretching far beyond the perioperative period. ${ }^{50-53}$

Both short- and longer-term mortality may be influenced by inequality of access to healthcare, and the standard of both acute and community medical care available. Specifically of relevance to patients undergoing colorectal surgery are rates of participation in cancer screening programmes, which are also known to be influenced by socioeconomic inequality. ${ }^{10}$ Early detection resulting in less advanced disease stage at the time of surgery can influence both short-term and longer-term postoperative mortality.

Emergency hospital admission rates are associated with socioeconomic inequality, ${ }^{54}$ and emergency surgery is associated with worse surgical outcomes. ${ }^{55}$ Some studies reported surgical urgency and 
adjusted for this in their analysis, but many did not. Increased rates of late presentations with cancer may predispose patients from lower socioeconomic backgrounds to receiving palliative rather than definitive curative surgery, with consequent adverse effect on longer-term outcomes.

Associations between socioeconomic group and outcome were found across different healthcare systems. The United Kingdom, Denmark, and Sweden each have healthcare systems organised around universal access funded through general taxation, with comparatively small coexisting private insurance based services. Australia also has a universal healthcare system funded through taxation, although the coexisting system funded through private insurance is comparatively larger. In the USA the system for the general population is based on private insurance premiums. However, there are several government-run schemes to assist those without private health insurance, older patients, military veterans, or patients with certain chronic conditions or disabilities. The Netherlands and France organise healthcare based on mandatory health insurance supplemented by a mixture of optional additional insurance or out-of-pocket payments. Taiwan operates a single-payer system funded through mandatory income-based insurance premiums, which is supplemented with out-ofpocket payments or direct government funding.

In studies from countries with privatised healthcare systems and based on insurance or payer status, it is notable that there is a relationship between social group and longer-term outcomes. More disadvantaged patients may have a lower baseline level of health coupled with limited access to healthcare throughout their lifetime, which would have an impact well beyond an acute surgical presentation. However, using insurance or payer status as a surrogate for socioeconomic group may be misleading. The specifics of different insurance policies may mean variations in co-payment charges, out of pocket expenses, or restrictions applied within managed care plans, all of which may impact on access to healthcare amongst patients categorised as having commercial insurance.

While inter-hospital variation in quality may occur in any healthcare system, a universal coverage system should reduce many of the barriers to access across the socioeconomic spectrum. ${ }^{56}$ However, a potential additional factor is the geographical distance from a patient's place of residence to appropriate medical care. The relationship between this and measures of socioeconomic group is 
complex. It may be the case in certain countries that residents in rural areas have lower income compared to those living in urban areas. However, deprivation as measured by a multifactorial index may be higher within cities, despite being geographically closer to large teaching hospitals, than in the surrounding suburbs or countryside.

In the privatised US healthcare system, some studies identified associations between patients' socioeconomic group and structural characteristics of the hospitals in which they received their treatment, such as hospital case volume, surgeon case volume, and overall rates of patients treated that were eligible for Medicaid. It is therefore possible that patients of lower socioeconomic group may cluster in certain hospitals. That being the case, hospital characteristics in units treating a high proportion of deprived patients may influence inequality in outcomes above and beyond the individual patients' risk factors, and may be potentially modifiable.

There was considerable heterogeneity in how studies included in this review were conducted and reported. For example, the variation in definitions of socioeconomic group, even when a single tool is used, makes comparisons difficult.

The majority of studies were based on analysis of administrative databases or registries. These data may have been entered retrospectively by non-clinicians who were not involved in the individual patient's care, and this presents potential issues with data accuracy. While there is the possibility of coding errors or coding based on incomplete documentation, previous analysis of the performance of tools such as the Charlson and Elixhauser indices extracted from administrative databases have shown good correlation with mortality outcomes. ${ }^{57}$

As with all scientific literature, particularly if based on observational data, publication bias is a risk. However, this may not be a particular issue for this review since most studies did not set out to estimate the relationship between socioeconomic group and mortality, but instead reported an estimate of this relationship as a covariate as part of an analysis with a different focus. What remains unclear is whether differences in outcome between socioeconomic groups are due to variation in the 
delivery of healthcare or are related to confounding from uncaptured variables such as lifestyle factors.

Standardised definitions for risk factors used in case-mix adjustment models, most notably comorbidity, would enable better comparisons between studies. Generating a minimum dataset with consistent definitions would be a useful extension of work already under way to standardise the outcome measures used in perioperative research. ${ }^{58}$

It remains unclear which health or social factors are the predominant contributors to the association between lower socioeconomic group and higher postoperative mortality rates, and whether contributory factors are potentially modifiable through individual or population-level interventions. Further investigation of the effects of inequality in health literacy, access to good quality primary care, engagement with screening programmes, or variations in hospital structures and processes may identify potential strategies for addressing variation in outcomes between socioeconomic groups.

From a health service perspective, it may be that reducing variation in care within and between hospitals around the time of surgery could help to reduce the effects of deprivation. However, given the perioperative period represents only a small part of the overall picture, it seems more likely that broader public health initiatives aimed at lifestyle related risk factors, health literacy, and engagement with healthcare services, plus coordinated national strategies in areas such as economic policy, housing, education, training and skills would also be required. 


\section{Details of author contributions}

TEP - Study design, literature search, data extraction and quality assessment, preparation and redrafting of the manuscript.

TS - Data extraction and quality assessment, review of the manuscript.

PM - Quality assessment, review of the manuscript.

AR-G - Quality assessment, review of the manuscript.

RR - Study design, review of the manuscript.

SRM - Study design, review of the manuscript.

\section{Acknowledgements}

Thanks go to Simon Coates, Clinical Support Librarian at University College London, for his assistance in refining the database search strategies.

\section{Declarations of interest}

SRM is associate National Clinical Director for elective care with NHS England.

\section{Funding}

No specific funding was awarded to support this study.

TP receives funding from the NIAA Health Services Research Centre at the Royal College of Anaesthetists for his role as a research fellow.

SRM receives funding from the UCLH Biomedical Research Centre where she is member of the faculty; she also receives funding from the Health Foundation as an Improvement Science fellow and for her role as Director of the NIAA Health Services Research Centre at the Royal College of Anaesthetists.

RR and AR-G were supported (RR in part, AR-G fully) by the National Institute for Health Research (NIHR) Collaboration for Leadership in Applied Health Research and Care (CLAHRC) North Thames at Bart's Health NHS Trust.

The views expressed are those of the author(s) and not necessarily those of the NHS, the NIHR, the NIAA, or the Department of Health. 


\section{References}

1. Filipovic M, Goldacre MJ, Gill L. Elective surgery for aortic abdominal aneurysm: comparison of English outcomes with those elsewhere. Journal of epidemiology and community health $2007 ; 61(3): 226-231$

2. Qadura M, Pervaiz F, Harlock JA, Al-Azzoni A, Farrokhyar F, Kahnamoui K et al. Mortality and reintervention following elective abdominal aortic aneurysm repair. Journal of Vascular Surgery 2013;57(6):1676-1683

3. Morris EJA, Taylor EF, Thomas JD, Quirke P, Finan PJ, Coleman MP et al. Thirty-day postoperative mortality after colorectal cancer surgery in England. Gut 2011;60(6):806-813

4. Papachristofi O, Sharples LD, Mackay JH, Nashef SA, Fletcher SN, Klein AA et al. The contribution of the anaesthetist to risk-adjusted mortality after cardiac surgery. Anaesthesia 2016;71(2):138-146

5. Siregar S, Groenwold RH, de Mol BA, Speekenbrink RG, Versteegh MI, Brandon Bravo Bruinsma GJ et al. Evaluation of cardiac surgery mortality rates: 30-day mortality or longer follow-up? European Journal of Cardio-Thoracic Surgery 2013;44(5):875-883

6. NELA Project Team. Second Patient Report of the National Emergency Laparotomy Audit. RCoA, London, 2016

7. Pujades-Rodriguez M, Timmis A, Stogiannis D, Rapsomaniki E, Denaxas S, Shah A et al. Socioeconomic deprivation and the incidence of 12 cardiovascular diseases in 1.9 million women and men: implications for risk prediction and prevention. PLOS ONE 2014;9(8):e104671

8. Barnett K, Mercer SW, Norbury M, Watt G, Wyke S, Guthrie B. Epidemiology of multimorbidity and implications for health care, research, and medical education: a crosssectional study. Lancet 2012;380(9836):37-43

9. Krajewski SA, Hameed SM, Smink DS, Rogers SO. Access to emergency operative care: A comparative study between the Canadian and American health care systems. Surgery 2009;146(2):300-307 
10. Smith SG, McGregor LM, Raine R, Wardle J, von Wagner C, Robb KA. Inequalities in cancer screening participation: examining differences in perceived benefits and barriers. PsychoOncology 2016;25(10):1168-1174

11. Fone DL, Farewell DM, White J, Lyons RA, Dunstan FD. Socioeconomic patterning of excess alcohol consumption and binge drinking: a cross-sectional study of multilevel associations with neighbourhood deprivation. BMJ Open 2013;3:e002337

12. Erskine S, Maheswaran R, Pearson T, Gleeson D. Socioeconomic deprivation, urban-rural location and alcohol-related mortality in England and Wales. BMC Public Health 2010;10(99)

13. Major JM, Doubeni CA, Freedman ND, Park Y, Lian M, Hollenbeck AR et al. Neighborhood socioeconomic deprivation and mortality: NIH-AARP diet and health study. PLoS ONE 2010;5(11):e15538

14. McNeill G, Masson LF, Macdiarmid JI, Craig LC, Wills WJ, Bromley C. Socio-economic differences in diet, physical activity and leisure-time screen use among Scottish children in 2006 and 2010: are we closing the gap? Public Health Nutrition 2017;20(6):951-958

15. Hiscock R, Bauld L, Amos A, Fidler JA, Munafò M. Socioeconomic status and smoking: a review. Annals of the New York Academy of Sciences 2012;1248:107-123

16. O'Kane MJ, McMenamin M, Bunting BP, Moore A, Coates VE. The relationship between socioeconomic deprivation and metabolic/cardiovascular risk factors in a cohort of patients with type 2 diabetes mellitus. Primary Care Diabetes 2010;4(4):241-249

17. Romeri E, Baker A, Griffiths C. Mortality by deprivation and cause of death in England and Wales, 1999-2003. Health Statistics Quarterly 2006;32:19-34

18. Kanervisto M, Vasankari T, Laitinen T, Heliövaara M, Jousilahti P, Saarelainen S. Low socioeconomic status is associated with chronic obstructive airway diseases. Respiratory Medicine 2011;105(8):1140-1146

19. Buck D, Maguire D. Inequalities in life expectancy: Changes over time and implications for policy. The King's Fund, London, 2015

20. Health state life expectancies by Index of Multiple Deprivation (IMD): England, 2013 to 2015. Office for National Statistics, London, 2017

21. Duncan GJ, Daly MC, McDonough P, Williams DR. Optimal Indicators of Socioeconomic Status for Health Research. American Journal of Public Health 2002;92(7):1151-1157 
22. Shavers VL. Measurement of socioeconomic status in health disparities research. Journal of the National Medical Association 2007;99(9):1013-1023

23. Barratt H, Rojas-García A, Clarke K, Moore A, Whittington C, Stockton S et al. Epidemiology of Mental Health Attendances at Emergency Departments: Systematic Review and MetaAnalysis. PLOS ONE 2016;11(4):e0154449

24. Abel GA, Barclay ME, Payne RA. Adjusted indices of multiple deprivation to enable comparisons within and between constituent countries of the UK including an illustration using mortality rates. BMJ Open 2016;6(11):e012750

25. Nur U, Rachet B, Parmar MK, Sydes MR, Cooper N, Lepage C et al. No socioeconomic inequalities in colorectal cancer survival within a randomised clinical trial. British Journal of Cancer 2008;99(11):1923-1928

26. Whynes DK, Frew EJ, Manghan CM, Scholefield JH, Hardcastle JD. Colorectal cancer, screening and survival: the influence of socio-economic deprivation. Public Health 2003;117(6):389-395

27. Oliphant R, Nicholson GA, Horgan PG, Molloy RG, McMillan DC, Morrison DS. Deprivation and colorectal cancer surgery: Longer-term survival inequalities are due to differential postoperative mortality between socioeconomic groups. Annals of Surgical Oncology 2013;20(7):2132-2139

28. Paulson EC, Mahmoud NN, Wirtalla C, Armstrong K. Acuity and survival in colon cancer surgery. Diseases of the Colon \& Rectum 2010;53(4):385-392

29. Rogers SO, Jr., Wolf RE, Zaslavsky AM, Wright WE, Ayanian JZ. Relation of surgeon and hospital volume to processes and outcomes of colorectal cancer surgery. Annals of Surgery 2006;244(6):1003-1011

30. Roxburgh CSD, Platt JJ, Leitch EF, Kinsella J, Horgan PG, McMillan DC. Relationship between preoperative comorbidity, systemic inflammatory response, and survival in patients undergoing curative resection for colorectal cancer. Annals of Surgical Oncology 2011;18(4):997-1005

31. Schootman M, Lian M, Pruitt SL, Hendren S, Mutch M, Deshpande AD et al. Hospital and geographic variability in two colorectal cancer surgery outcomes: complications and mortality after complications. Annals of Surgical Oncology 2014;21(8):2659-2666 
32. Hole DJ, McArdle CS. Impact of socioeconomic deprivation on outcome after surgery for colorectal cancer. British Journal of Surgery 2002;89(5):586-590

33. Kim Y-E, Gatrell AC, Francis BJ. The geography of survival after surgery for colorectal cancer in southern England. Social Science \& Medicine 2000;50:1099-1107

34. Lyratzopoulos G, Scheridan GF, Michie HR, McElduff P, Hobbiss JH. Absence of socioeconomic variation in survival from colorectal cancer in patients receiving surgical treatment in one health district: Cohort study. Colorectal Disease 2004;6(6):512-517

35. McArdle CS, Hole DJ. Outcome following surgery for colorectal cancer. British Medical Bulletin 2002;64:119-125

36. McMillan DC, Canna K, McArdle CS. The effect of deprivation and the systemic inflammatory response on outcome following curative resection for colorectal cancer. British Journal of Cancer 2003;89(4):612-614

37. Faiz O, Warusavitarne J, Bottle A, Tekkis PP, Clark SK, Darzi AW et al. Nonelective Excisional Colorectal Surgery in English National Health Service Trusts: A Study of Outcomes from Hospital Episode Statistics Data between 1996 and 2007. Journal of the American College of Surgeons 2010;210(4):390-401

38. Faiz O, Brown T, Bottle A, Burns EM, Darzi AW, Aylin P. Impact of Hospital institutional volume on postoperative mortality after major emergency colorectal surgery in English National Health Service trusts, 2001 to 2005. Diseases of the Colon and Rectum 2010;53(4):393-401

39. Faiz O, Warusavitarne J, Bottle A, Tekkis PP, Darzi AW, Kennedy RH. Laparoscopically assisted vs. open elective colonic and rectal resection: A comparison of outcomes in english national health service trusts between 1996 and 2006. Diseases of the Colon and Rectum 2009;52(10):1695-1704

40. Frederiksen BL, Osler M, Harling H, Ladelund S, Jorgensen T. The impact of socioeconomic factors on 30-day mortality following elective colorectal cancer surgery: A nationwide study. European Journal of Cancer 2009;45(7):1248-1256

41. Birkmeyer NJO, Gu N, Baser O, Morris AM, Birkmeyer JD. Socioeconomic status and surgical mortality in the elderly. Medical Care 2008;46(9):893-899 
42. Csikesz NG, Singla A, Simons JP, Tseng JF, Shah SA. The impact of socioeconomic status on presentation and treatment of diverticular disease. Journal of Gastrointestinal Surgery 2009;13(11):1993-2001; discussion 2001-1992

43. Dimick JB, Cowan JA, Jr, Upchurch GR, Jr, Colletti LM. Hospital volume and surgical outcomes for elderly patients with colorectal cancer in the United States. Journal of Surgical Research 2003;114(1):50-56

44. Hannan EL, Radzyner M, Rubin D, Dougherty J, Brennan MF. The influence of hospital and surgeon volume on in-hospital mortality for colectomy, gastrectomy, and lung lobectomy in patients with cancer. Surgery 2002;131(1):6-15

45. Harmon JW, Tang DG, Gordon TA, Bowman HM, Choti MA, Kaufman HS et al. Hospital volume can serve as a surrogate for surgeon volume for achieving excellent outcomes in colorectal resection. Annals of Surgery 1999;230(3):404-411

46. Kaplan GG, McCarthy EP, Ayanian JZ, Korzenik J, Hodin R, Sands BE. Impact of hospital volume on postoperative morbidity and mortality following a colectomy for ulcerative colitis. Gastroenterology 2008;134(3):680-687

47. Schrag D, Cramer LD, Bach PB, Cohen AM, Warren JL, Begg CB. Influence of hospital procedure volume on outcomes following surgery for colon cancer. JAMA 2000;284(23):30283035

48. Greenstein AJ, Romanoff AM, Moskowitz AJ, Sosunov EA, Khaitov S, Egorova NN. Payer status and access to laparoscopic subtotal colectomy for ulcerative colitis. Diseases of the Colon \& Rectum 2013;56(9):1062-1067

49. LaPar DJ, Bhamidipati CM, Mery CM, Stukenborg GJ, Jones DR, Schirmer BD et al. Primary payer status affects mortality for major surgical operations. Annals of Surgery 2010;252(3):544-550; discussion 550-541

50. Khuri SF, Henderson WG, DePalma RG, Mosca C, Healey NA, Kumbhani DJ. Determinants of long-term survival after major surgery and the adverse effect of postoperative complications. Annals of Surgery 2005;242(3):326-341

51. Burns EM, Bottle A, Aylin P, Darzi A, John Nicholls R, Faiz O. Variation in reoperation after colorectal surgery in England as an indicator of surgical performance: Retrospective analysis of Hospital Episode Statistics. BMJ (Online) 2011;343:d4836 
52. Dik VK, Aarts MJ, Van Grevenstein WMU, Koopman M, Van Oijen MGH, Lemmens VE et al. Association between socioeconomic status, surgical treatment and mortality in patients with colorectal cancer. British Journal of Surgery 2014;101(9):1173-1182

53. Kelz RR, Gimotty PA, Polsky D, Norman S, Fraker D, DeMichele A. Morbidity and mortality of colorectal carcinoma surgery differs by insurance status. Cancer 2004;101(10):2187-2194

54. Sheringham J, Asaria M, Barratt $H$, Raine R, Cookson R. Are some areas more equal than others? Socioeconomic inequality in potentially avoidable emergency hospital admissions within English local authority areas. Journal of Health Services \& Research Policy 2017;22(2):83-90

55. McLean RC, McCallum IJ, Dixon S, O'Loughlin P. A 15-year retrospective analysis of the epidemiology and outcomes for elderly emergency general surgical admissions in the North East of England: A case for multidisciplinary geriatric input. International Journal Of Surgery 2016;28:13-21

56. Asaria M, Ali S, Doran T, Ferguson B, Fleetcroft R, Goddard M et al. How a universal health system reduces inequalities: lessons from England. Journal of epidemiology and community health 2016;70(7):637-643

57. Li B, Evans D, Faris P, Dean S, Quan H. Risk adjustment performance of Charlson and Elixhauser comorbidities in ICD-9 and ICD-10 administrative databases. BMC Health Services Research 2008;8(12)

58. Myles PS, Grocott MP, Boney O, Moonesinghe SR. Standardizing end points in perioperative trials: towards a core and extended outcome set. British Journal of Anaesthesia 2016;116(5):586-589

59. Akinyemiju T, Meng Q, Vin-Raviv N. Race/ethnicity and socio-economic differences in colorectal cancer surgery outcomes: Analysis of the nationwide inpatient sample. BMC Cancer 2016;16(1):715

60. Amini A, Yeh N, Jones BL, Bedrick E, Vinogradskiy $Y$, Rusthoven CG et al. Perioperative Mortality in Nonelderly Adult Patients With Cancer: A Population-based Study Evaluating Health Care Disparities in the United States According to Insurance Status. American Journal of Clinical Oncology 2016:[Epub ahead of print] 
61. Barclay KL, Goh PJ, Jackson TJ. Socio-economic disadvantage and demographics as factors in stage of colorectal cancer presentation and survival. ANZ Journal of Surgery 2015;85(3):135-139

62. Beckmann K, Moore J, Wattchow D, Young G, Roder D. Short-term outcomes after surgical resection for colorectal cancer in South Australia. Journal of Evaluation in Clinical Practice 2016;23(2):316-324

63. Bennett KM, Scarborough JE, Pappas TN, Kepler TB. Patient socioeconomic status is an independent predictor of operative mortality. Annals of Surgery 2010;252(3):552-557; discussion 557-558

64. Bharathan B, Welfare M, Borowski DW, Mills SJ, Steen IN, Kelly SB et al. Impact of deprivation on short- and long-term outcomes after colorectal cancer surgery. British Journal of Surgery 2011;98(6):854-865

65. de Vries S, Jeffe DB, Davidson NO, Deshpande AD, Schootman M. Postoperative 30-day mortality in patients undergoing surgery for colorectal cancer: development of a prognostic model using administrative claims data. Cancer Causes \& Control 2014;25(11):1503-1512

66. ELHadi A, Ashford-Wilson S, Brown S, Pal A, Lal R, Aryal K. Effect of social deprivation on the stage and mode of presentation of colorectal cancer. Annals of Coloproctology 2016;32(4):128-132

67. Frederiksen BL, Osler M, Harling H, Ladelund S, Jorgensen T. Do patient characteristics, disease, or treatment explain social inequality in survival from colorectal cancer? Social Science \& Medicine 2009;69(7):1107-1115

68. Glen P, Simpson MF, Donnelly L, Leonard S, Macdonald A. Thirty-day mortality from colorectal cancer surgery within a deprived population. Colorectal Disease 2005;7(2):193-195

69. Gooiker GA, Dekker JW, Bastiaannet E, van der Geest LG, Merkus JW, van de Velde CJ et al. Risk factors for excess mortality in the first year after curative surgery for colorectal cancer. Annals of Surgical Oncology 2012;19(8):2428-2434

70. Harris AR, Bowley DM, Stannard A, Kurrimboccus S, Geh JI, Karandikar S. Socioeconomic deprivation adversely affects survival of patients with rectal cancer. British Journal of Surgery 2009;96(7):763-768 
71. Jorgensen ML, Young JM, Dobbins TA, Solomon MJ. Predictors of variation in colorectal cancer care and outcomes in New South Wales: a population-based health data linkage study. Medical Journal of Australia 2014;200(7):403-407

72. Kee F, Wilson RH, Harper C, Patterson CC, McCallion K, Houston RF et al. Influence of hospital and clinician workload on survival from colorectal cancer: cohort study. British Medical Journal 1999;318(7195):1381-1386

73. Kim J, Artinyan A, Mailey B, Christopher S, Lee W, McKenzie S et al. An interaction of race and ethnicity with socioeconomic status in rectal cancer outcomes. Annals of Surgery $2011 ; 253(4): 647-654$

74. Ko CY, Chang JT, Chaudhry S, Kominski G. Are high-volume surgeons and hospitals the most important predictors of inhospital outcome for colon cancer resection? Surgery 2002;132(2):268-273

75. Lincourt AE, Sing RF, Kercher KW, Stewart A, Demeter BL, Hope WW et al. Association of demographic and treatment variables in long-term colon cancer survival. Surgical Innovation 2008;15(1):17-25

76. Liu CJ, Huang N, Lin CC, Lee YT, Hu YW, Yeh CM et al. Outcome disparities between medical personnel and nonmedical personnel patients receiving definitive surgery for colorectal cancer: A nationwide population-based study. Medicine 2015;94(4):e402

77. McArdle CS, Hole DJ. Influence of volume and specialization on survival following surgery for colorectal cancer. British Journal of Surgery 2004;91(5):610-617

78. McArdle CS, Hole DJ. Outcome following surgery for colorectal cancer: analysis by hospital after adjustment for case-mix and deprivation. British Journal of Cancer 2002;86(3):331-335

79. Monnet E, Boutron MC, Faivre J, Milan C. Influence of socioeconomic status on prognosis of colorectal cancer: A population-based study in Cote D'Or, France. Cancer 1993;72(4):11651170

80. Oliphant R, Nicholson GA, Horgan PG, Molloy RG, McMillan DC, Morrison DS. Contribution of surgical specialization to improved colorectal cancer survival. British Journal of Surgery 2013;100(10):1388-1395

81. Olsson LI, Granstrom F. Socioeconomic inequalities in relative survival of rectal cancer most obvious in stage III. World Journal of Surgery 2014;38(12):3265-3275 
82. Reames BN, Birkmeyer NJO, Dimick JB, Ghaferi AA. Socioeconomic disparities in mortality after cancer surgery : Failure to rescue. JAMA Surgery 2014;149(5):475-481

83. Rhoads KF, Ackerson LK, Jha AK, Dudley RA. Quality of colon cancer outcomes in hospitals with a high percentage of Medicaid patients. Journal of the American College of Surgeons 2008;207(2):197-204

84. Sabik LM, Bradley CJ. Differences in mortality for surgical cancer patients by insurance and hospital safety net status. Medical Care Research \& Review 2013;70(1):84-97

85. Schootman M, Lian M, Pruitt SL, Deshpande AD, Hendren S, Mutch M et al. Hospital and geographic variability in thirty-day all-cause mortality following colorectal cancer surgery. Health Services Research 2014;49(4):1145-1164

86. Smith JJ, Tilney HS, Heriot AG, Darzi AW, Forbes H, Thompson MR et al. Social deprivation and outcomes in colorectal cancer. British Journal of Surgery 2006;93(9):1123-1131

87. Tilney H, Lovegrove RE, Smith JJ, Thompson MR, Tekkis PP. The national bowel cancer project: Social deprivation is an independent predictor of nonrestorative rectal cancer surgery. Diseases of the Colon and Rectum 2009;52(6):1046-1053

88. Warwick J, Will O, Allgood P, Miller R, Duffy S, Greenberg D. Variation in colorectal cancer treatment and survival: a cohort study covering the East Anglia region. Colorectal Disease 2013;15(10):1243-1252 
Table 1

Potential confounding variables included in statistical models

\begin{tabular}{lll}
\hline Patient factors & $\begin{array}{l}\text { Surgical or treatment } \\
\text { factors }\end{array}$ & Hospital or surgeon factors \\
\hline Age & Previous colonoscopy & Hospital case volume \\
Sex & Disease stage or grade & Hospital location \\
Ethnicity & Disease site & Hospital type \\
Insurance status & Urgency & Surgeon age \\
Income & Surgical approach & Surgeon sex \\
Residential area & Surgical procedure & Surgeon experience \\
Marital status & Histology & Surgeon specialisation \\
Cohabiting status & Lymph nodes & Surgeon case volume \\
Education & Reoperation & \\
Comorbidity & Postoperative complications & \\
Smoking history & Adjuvant therapy & \\
Body mass index & & \\
C Reactive Protein & &
\end{tabular}


Table 2

Summary of findings for the most common descriptors of socioeconomic group and follow-up interval

\begin{tabular}{|c|c|c|c|}
\hline & & $\begin{array}{l}\text { Short-term } \\
\text { mortality } \\
\text { (In-hospital or } \\
\text { 30-day) }\end{array}$ & $\begin{array}{l}\text { Longer-term } \\
\text { mortality } \\
\text { (1-5 year survival, } \\
\text { or overall survival } \\
\text { time) }\end{array}$ \\
\hline $\begin{array}{l}\text { Multifactorial } \\
\text { index }\end{array}$ & $\begin{array}{l}\text { Total number of studies } \\
\text { Difference on unadjusted analysis } \\
\text { Difference on adjusted analysis }\end{array}$ & $\begin{array}{l}17 \\
4 \text { out of } 9 \\
6 \text { out of } 11\end{array}$ & $\begin{array}{l}21 \\
6 \text { out of } 12 \\
10 \text { out of } 16\end{array}$ \\
\hline $\begin{array}{l}\text { Insurance or } \\
\text { payer status }\end{array}$ & $\begin{array}{l}\text { Total number of studies } \\
\text { Difference on unadjusted analysis } \\
\text { Difference on adjusted analysis }\end{array}$ & $\begin{array}{l}7 \\
2 \text { out of } 2 \\
1 \text { out of } 6\end{array}$ & $\begin{array}{l}3 \\
1 \text { out of } 1 \\
2 \text { out of } 3\end{array}$ \\
\hline $\begin{array}{l}\text { Income or } \\
\text { poverty }\end{array}$ & $\begin{array}{l}\text { Total number of studies } \\
\text { Difference on unadjusted analysis } \\
\text { Difference on adjusted analysis }\end{array}$ & $\begin{array}{l}5 \\
2 \text { out of } 3 \\
5 \text { out of } 5\end{array}$ & $\begin{array}{l}8 \\
2 \text { out of } 2 \\
7 \text { out of } 8\end{array}$ \\
\hline
\end{tabular}

A single paper may appear more than once 
Table 3

Study attributes and numbers of patients included

\begin{tabular}{llllll}
\hline & & Studies & & Patients & \\
& & Number & $(\%)$ & Number & $(\%)$ \\
\hline Deprivation & Multifactorial index & 28 & $(47.5)$ & 790372 & $(29.3)$ \\
& Income or poverty & 17 & $(28.8)$ & 845024 & $(31.3)$ \\
& Insurance or payer status & 15 & $(25.4)$ & 618702 & $(22.9)$ \\
& Other & 6 & $(10.2)$ & 653252 & $(24.2)$ \\
\hline Comorbidities & Charlson score & 22 & $(37.3)$ & 1313961 & $(48.7)$ \\
& Elixhauser score & 6 & $(10.2)$ & 954503 & $(35.4)$ \\
& ASA & 3 & $(5.1)$ & 14858 & $(0.6)$ \\
& Other & 7 & $(11.9)$ & 126785 & $(4.7)$ \\
\hline Urgency of & Non-elective and elective & 35 & $(59.3)$ & 1225276 & $(45.4)$ \\
surgery & Elective & 3 & $(5.1)$ & 200082 & $(7.4)$ \\
& Non-elective & 3 & $(5.1)$ & 119873 & $(4.4)$ \\
& Not reported & 19 & $(32.2)$ & 1155441 & $(42.8)$ \\
\hline Aims of & Curative & 11 & $(18.6)$ & 89055 & $(3.3)$ \\
surgery & Curative and palliative & 7 & $(11.9)$ & 27063 & $(1.0)$ \\
& Palliative & 2 & $(3.4)$ & 1664 & $(0.1)$ \\
& Not reported & 41 & $(69.5)$ & 2581586 & $(95.7)$ \\
\hline Data & 1976-1999 & 20 & $(33.9)$ & 348925 & $(12.9)$ \\
collection & 2000-2014 & 27 & $(45.8)$ & 1717170 & $(63.6)$ \\
\hline Country & United Kingdom & 25 & $(42.4)$ & 778985 & $(28.9)$ \\
& United States of America & 24 & $(40.7)$ & 1810347 & $(67.1)$ \\
& Australia & 3 & $(5.1)$ & 11387 & $(0.4)$ \\
& Denmark & 2 & $(3.4)$ & 15923 & $(0.6)$ \\
& Netherlands & 2 & $(3.4)$ & 8359 & $(0.3)$ \\
& Taiwan & 1 & $(1.7)$ & 61728 & $(2.3)$ \\
& Sweden & 1 & $(1.7)$ & 11355 & $(0.4)$ \\
& France & 1 & $(1.7)$ & 319 & $(<0.1)$
\end{tabular}

A single paper may appear more than once in a given category 
MEDLINE search $=10417$

EMBASE search $=10221$

The Cochrane Library search $=5775$

Web of Science search $=2675$

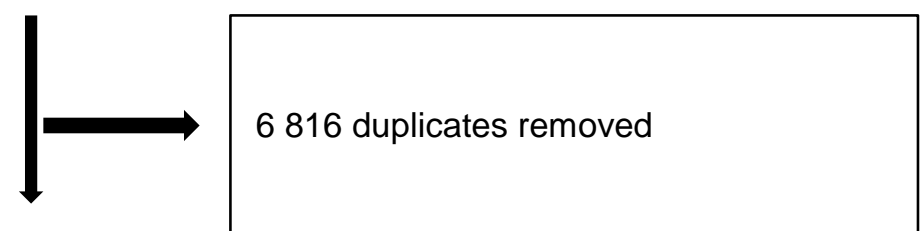

22272 articles screened

22077 excluded after review of title and abstract as not relevant to the research question

195 full text articles reviewed

134 excluded based on inclusion and exclusion criteria

2075 articles screened through hand searching of reference lists and citations. 6 additional eligible articles identified.

59 articles included in the final review

Figure 1: Study selection diagram

Poulton et al 


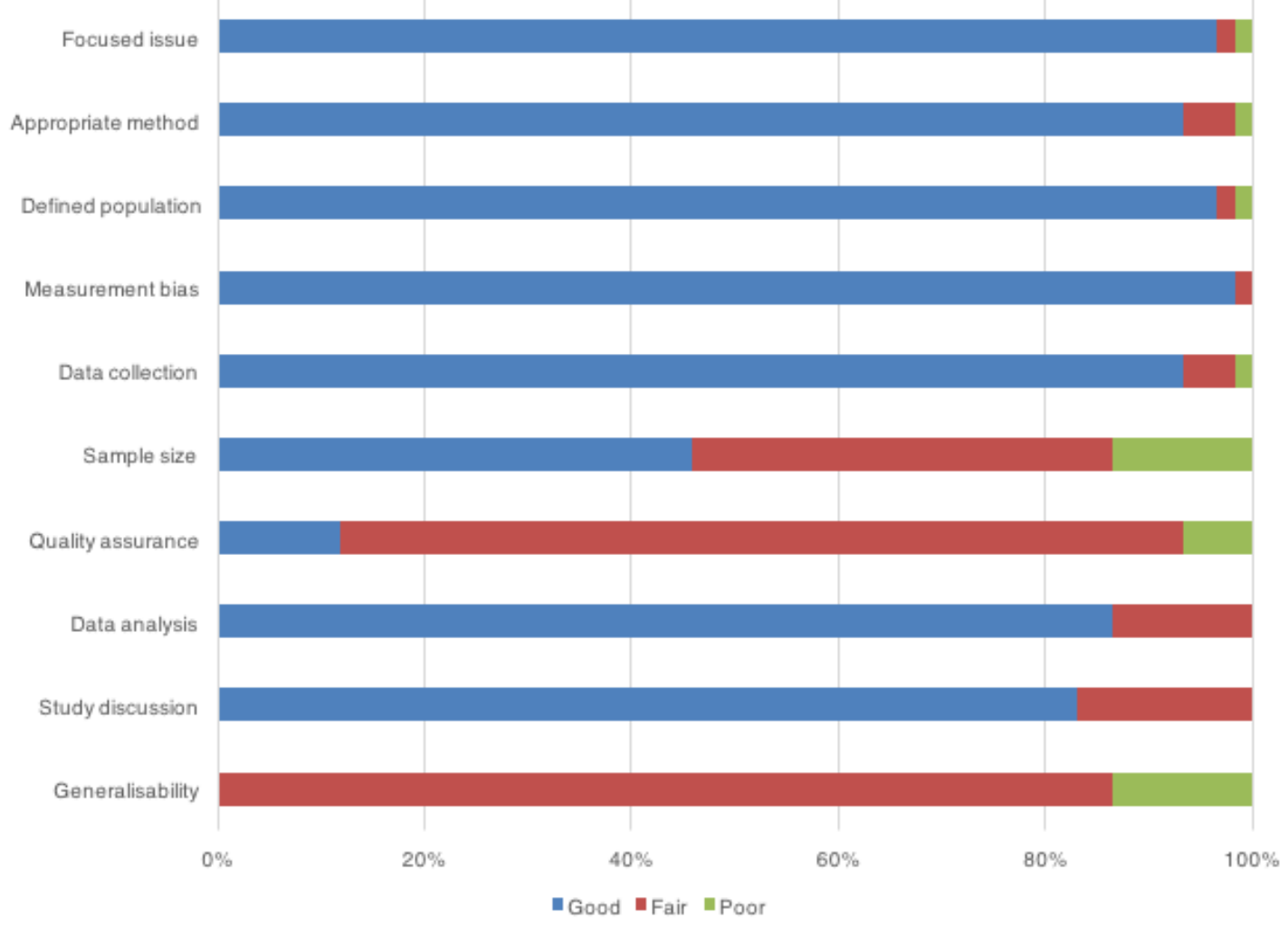

Figure 2: Assessment of quality of included studies Poulton et al 